\title{
VAPORIZAÇÃO NO ALÍVIO DAS TENSÕES DE CRESCIMENTO EM TORAS DE Eucalyptus dunnii DE DUAS PROCEDÊNCIAS
}

\section{VAPORIZATION ON THE RELIASE OF GROWTH STRESSES IN LOGS OF Eucalyptus dunnii FROM TWO ORIGIN}

\author{
Elias Taylor Durgante SEVERO ${ }^{1} \Xi^{\circ}$ \\ Ivan TOMASELLI ${ }^{2}$
}

\begin{abstract}
RESUMO
O objetivo dessa pesquisa foi analisar o efeito do tratamento de anelamento e vaporização no alívio das tensões de crescimento em toras de duas procedências de Eucalyptus dunnii. Para isso, inicialmente foi realizado tratamento de anelamento com motosserra e posteriormente vaporização das toras, a $100^{\circ} \mathrm{C}$ por $20 \mathrm{~h}$. A avaliação do efeito desses tratamentos foi realizada medindo-se as rachaduras, a abertura das tábuas em relação à tora durante o desdobro e os empenamentos. Os resultados obtidos mostraram que o tratamento foi eficiente e reduziu a abertura das tábuas em relação à tora e o comprimento e a largura das rachaduras em ambas as procedências testadas.
\end{abstract}

Palavras-chave: Eucalyptus dunnii, anelamento, vaporização, tensões de crescimento.

\begin{abstract}
The objective of this research was to analyze the effect of ringment and vaporization treatments on the release of growth stresses in logs of two Eucalyptus dunnii. In order to do that, a ringment treatment was performed with a chain saw and later, logs were steamed at $100^{\circ} \mathrm{C}$ during 20 hours. The assessment of these treatment's effects was done by analyzing measuring the cracks, gaps on boards in relation on the log during the sawing process and warping. The results showed that the treatment was efficient and decreased the gap on the boards in relation to the log, length and size of the splits for both proceedings tested.
\end{abstract}

Key-Words: Eucalyptus dunnii, ringment, vaporization, growth stresses.

\footnotetext{
1 Engenheiro Florestal, Professor Doutor do Departamento de Recursos Naturais, Universidade Estadual Paulista - UNESP, Caixa Postal 237, CEP 18603-970, Botucatu, SP. $\cong$ Autor para correspondência.

${ }^{2}$ Engenheiro Florestal, Professor Titular do Departamento de Engenharia e Tecnologia Florestal, Universidade Federal do Paraná - UFPR, CEP 80.210-170, Curitiba, PR.
} 


\section{INTRODUÇÃO}

A importância das espécies do gênero Eucalyptus para o setor florestal-madeireiro é indiscutível. O Brasil é detentor de mais de um quarto de toda a superfície plantada no globo terrestre com este gênero, produzindo cerca de trinta milhões de metros cúbicos de madeira anualmente. Por suas características físico-mecânicas a madeira do eucalipto apresenta-se como alternativa para a substituição de espécies nativas consagradas, podendo contribuir significativamente para o suprimento das demandas interna e externa. Entretanto, até o momento a utilização do eucalipto em larga escala é restrita à produção de pasta para fabricação de papel, carvão vegetal, chapas de fibra e partículas. O seu emprego para outros usos finais tem causado frustrações durante o processamento da madeira, devido ao aparecimento de inúmeros defeitos, que conduzem a consideráveis perdas de matéria-prima e, conseqüentemente, econômicas.

Entre os problemas na utilização do eucalipto, em particular como madeira serrada para fins diversos, estão as tensões de crescimento, a elevada retratibilidade e o colapso durante a secagem.

Muitas árvores desenvolvem tensões de crescimento. A madeira próxima à casca sofre uma tração na direção longitudinal. Aproximando-se da medula, ocorre uma compressão na mesma direção. Uma segunda tensão ocorre transversalmente à tora, onde a madeira próxima à casca sofre uma compressão e a próxima da medula uma força de tração. A combinação dessas tensões tende a causar rachaduras no topo das toras quando cortadas transversalmente.

Chafe (1979) e Kubler (1987) comentam sobre a possibilidade da liberação das tensões de crescimento pelo relaxamento das deformações por meio da aplicação simultânea de umidade e calor, promovendo assim uma nova acomodação das células ou de componentes das paredes celulares. Ainda, segundo Kubler (1987), a madeira com relaxamento de tensões continua com a deformação já admitida, mas essa deformação é transformada de elástica em plástica e, portanto, tal material não tem tendência a contrair, expandir, empenar ou rachar.

De acordo com resultados obtidos pelo U.S. Forest Products Laboratory (1987), a madeira submetida ao aquecimento em temperatura de $82^{\circ} \mathrm{C}$ pode, em alguns casos, reduzir cerca de $90 \%$ ou mais das tensões de crescimento. Caso as toras sejam aquecidas com comprimentos longos e então secionadas, o novo topo desenvolverá menos rachaduras.

Skolmen (1967) obteve reduções de cerca de $50 \%$ das tensões de crescimento em toras de Eucalyptus saligna com diâmetro de 15 a $20 \mathrm{~cm}$ após um tratamento de $24 \mathrm{~h}$ em água quente. Um segundo tratamento realizado pelo autor, porém com aplicação de vapor saturado à pressão atmosférica durante 48 h, não demonstrou aparente melhora na liberação das tensões de crescimento.

Diversos outros autores trabalhando em diferentes condições também verificaram o efeito posterior do aquecimento. Lutz e Panzer (1969) obtiveram completo relaxamento das tensões de crescimento após $48 \mathrm{~h}$ de aquecimento em água quente a $93^{\circ} \mathrm{C}$, sendo que a $65^{\circ} \mathrm{C}$ o tratamento aliviou cerca de dois terços destas tensões. Weik et al. (1984) observaram que a vaporização de toras de Yellow poplar (Liriodendron tulipifera L.) por mais de $10 \mathrm{~h}$ reduziu significativamente as tensões de crescimento. Okuyama et al. (1987) obtiveram resultados favoráveis na liberação das tensões de crescimento em toras de Elms (Zelkova serrata Maquino), quando aquecidas por meio de vapores (fumaça quente à temperatura de 150 a $200^{\circ} \mathrm{C}$ por mais de 40 h). Kikata (1995) demonstrou que a aplicação de vapor saturado nas temperaturas de $90^{\circ} \mathrm{C}, 110^{\circ} \mathrm{C}$ e $140^{\circ} \mathrm{C}$ durante $3 \mathrm{~h}$ em toras verdes de Eucalyptus rubida reduziu as tensões de crescimento de forma crescente com a temperatura empregada.

Esse estudo teve como objetivo analisar o efeito do tratamento de anelamento e vaporização no alívio das tensões de crescimento, em toras de duas procedências de Eucalyptus dunnii.

\section{METODOLOGIA}

Para realização do estudo, utilizaram-se toras de Eucalyptus dunnii das procedências Urbenville e Dorrigo, de plantio de propriedade da Empresa Brasileira de Pesquisa Agropecuária (EMBRAPA), localizado no município de Colombo-PR.

A coleta do material envolveu o corte, ao acaso, de 12 árvores de Eucalyptus dunnii, sendo seis da procedência Urbenville e seis da procedência Dorrigo.

O planejamento para utilização das árvores obedeceu ao princípio do sortimento ou uso múltiplo, no qual as toras de maior diâmetro são destinadas à laminação, as toras de diâmetro médio são utilizadas para a fabricação de madeira serrada e o restante (com diâmetro inferior a $20 \mathrm{~cm}$ ) é utilizado para chapas de composição, celulose e papel, energia etc. Esse estudo deteve-se somente nas toras destinadas à utilização como madeira serrada.

Os tratamentos para alívio das tensões de crescimento constituíram-se em anelamento em todas as árvores e toras e, posteriormente, em vaporização de parte das toras envolvidas no estudo. O primeiro anelamento foi realizado quando a árvore ainda encontrava-se em pé, sendo 
realizado com motosserra a uma profundidade de um terço do raio da árvore, deixando-se uma distância de 20 a $30 \mathrm{~cm}$ entre o anelamento e o corte transversal da árvore. O segundo foi realizado durante o dimensionamento das toras, novamente realizado com motosserra na mesma profundidade, porém, nesse caso, deixando-se uma distância de $15 \mathrm{~cm}$ de cada extremo da tora. Esse segundo anelamento foi realizado logo após a derrubada das árvores.

De cada árvore foram retiradas três toras com 2,4 m de comprimento, sendo que desse total, uma tora foi mantida como controle e as duas restantes submetidas a tratamento de vaporização.

As toras foram vaporizadas em tanques apropriados, durante um período de $20 \mathrm{~h}$, a $100^{\circ} \mathrm{C}$. Posteriormente, essas toras foram desdobradas em tábuas, realizando-se cortes tangenciais. Esse sistema de corte não é o mais apropriado para a espécie, no entanto, a sua adoção facilitou a verificação do efeito do tratamento de vaporização na qualidade da madeira serrada.

Para avaliação das tensões de crescimento, levou-se em consideração a forma como essas tensões manifestam-se na madeira serrada, ou seja, rachaduras, abertura das tábuas em relação à tora no momento do desdobro e empenamentos.
Para avaliação das rachaduras mediu-se o comprimento e a largura das rachaduras nas tábuas, tanto na entrada quanto na saída da serra (dois extremos das tábuas).

A abertura da tábua em relação à tora foi tomada quando a serra-fita encontrava-se a cerca de $2 \mathrm{~m}$ do comprimento final da tábua. Todas as medidas foram tomadas com paquímetros de precisão.

\section{RESULTADOS E DISCUSSÃO}

A avaliação visual das tábuas durante o desdobro indicaram que não houve nenhum tipo de empenamento, tanto em madeira proveniente de toras controle (aneladas), quanto das vaporizadas (aneladas e vaporizadas).

O mesmo, no entanto, não ocorreu para as variáveis abertura das tábuas em relação à tora e rachaduras. Para avaliação dessas variáveis foi realizada análise da variância, levando-se em consideração tanto o tratamento de vaporização quanto as procedências. O resumo dessa análise para a abertura das tábuas em relação à tora e comprimento e largura das rachaduras encontrase nas Tabelas 1 e 2 , respectivamente.

TABELA 1 - Abertura média das tábuas em relação à tora ${ }^{1}$

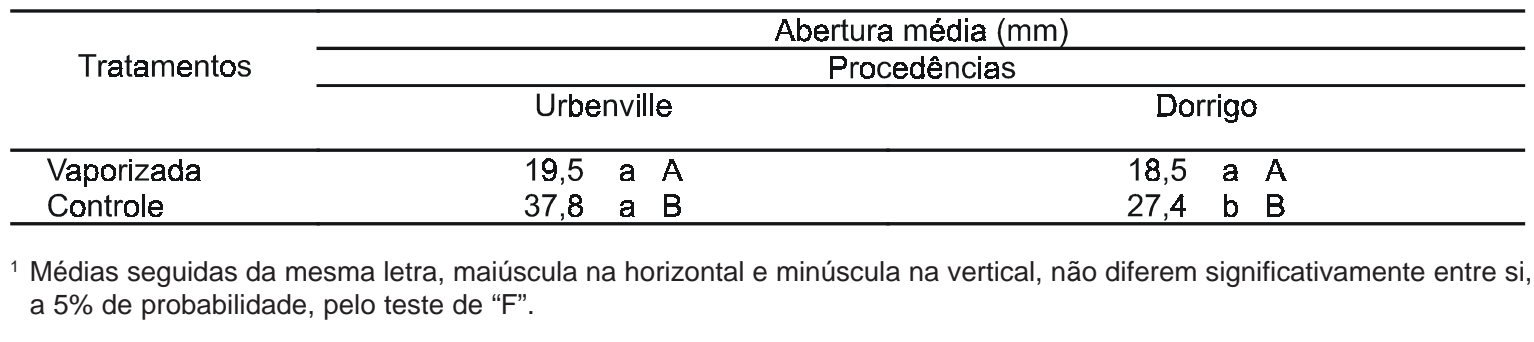

TABELA 2 - Comprimento e largura das rachaduras produzidas durante o desdobro ${ }^{1}$

\begin{tabular}{|c|c|c|c|c|c|c|c|}
\hline \multirow{3}{*}{ Tratamentos } & \multicolumn{3}{|c|}{ Comprimento médio das rachaduras (cm) } & \multicolumn{4}{|c|}{$\begin{array}{l}\text { Largura média das rachaduras } \\
(\mathrm{mm})\end{array}$} \\
\hline & \multicolumn{3}{|c|}{ Procedências } & \multicolumn{3}{|c|}{ Procedências } & \\
\hline & Urbenville & \multicolumn{2}{|c|}{ Dorrigo } & Urbenville & \multicolumn{3}{|c|}{ Dorrigo } \\
\hline Vaporizada & 57,8 a $\mathrm{A}$ & 52,8 & a $\mathrm{A}$ & 15,4 a $\mathrm{A}$ & 10,2 & $a$ & $\bar{A}$ \\
\hline Controle & 111,9 a $B$ & 86,7 & a $B$ & 31,4 & 22,2 & a & B \\
\hline
\end{tabular}

Conforme pode ser observado nas Tabelas 1 e 2, o tratamento de vaporização proporcionou redução significativa nas tensões de crescimento, representadas pelas variáveis abertura das tábuas em relação à tora e comprimento e largura das rachaduras, em ambas as procedências de Eucalyptus dunnii.
Verifica-se que a vaporização das toras reduziu a abertura das tábuas em relação à tora, o comprimento das rachaduras e a largura das rachaduras em $49 \%, 48 \%$ e $51 \%$, respectivamente, para a procedência Urbenville, e 33\%, 39\% e 54\%, respectivamente, para a procedência Dorrigo de Eucalyptus dunnii. A redução nas tensões de 
crescimento é atribuída à ação simultânea exercida por calor e umidade na madeira, provocando, dessa forma, a plasticização da lignina e o conseqüente rela-xamento das tensões (Chafe 1979; Kubler, 1987). Para Kubler (1987), a madeira com relaxamento das tensões continua com a deformação já admitida, mas essa deformação é transformada de elástica em plástica e, portanto, tal material não tem tendên-cia a contrair ou expandir e com isso empenar ou rachar.

Embora tenham-se obtido reduções consideráveis nas tensões de crescimento, na ordem de $50 \%$, não foi observado, em nenhuma das variáveis estudadas, sua eliminação completa. Estudos realizados por Skolmen (1967) mostram comportamento semelhante. $\mathrm{O}$ autor obteve reduções de cerca de $50 \%$ das tensões de crescimento em toras de Eucalyptus saligna após um tratamento de $24 \mathrm{~h}$ em água quente. Entretanto, estudo conduzido por Rozas (1993) com madeira de Eucalyptus grandis mostrou que a vaporização das toras, por período de $18 \mathrm{~h}$ à temperatura de $90^{\circ} \mathrm{C}$ foi suficiente para eliminar, por completo, as rachaduras desta espécie, além de reduzir consideravelmente a abertura das tábuas em relação à tora. Salienta ainda o autor que não houve diferença significativa entre o tempo de vaporização de $18 \mathrm{~h}$ e $36 \mathrm{~h}$, para as mesmas condições de temperatura.

A explicação para a diferença de comportamento das tensões de crescimento com o trata-mento de vaporização é dado por Chafe (1979). Segundo este autor, a diferença de comportamento das tensões de crescimento entre espécies é normal, sugerindo que estas podem ser substancialmente controladas por fatores genéticos. Para o autor, essa variação não existe somente entre espécies, mas também entre árvores de uma mesma espécie e até entre toras de uma mesma árvore.
Para Chafe (1979), enquanto as tensões de crescimento têm um embasamento teórico de origem biológica e mecânica, as causas específicas permanecem quase que completamente desconhecidas.

Entretanto, no que se refere ao efeito da procedência (procedência dentro dos tratamentos) nessa análise, com exceção apenas da variável abertura das tábuas em relação à tora, que em material controle demonstrou ser significativamente maior na procedência Urbenville, as demais variáveis, embora tenham apresentado reduções percentuais consideráveis, não mostraram diferença estatisticamente significativa. Esse fato é atribuído à grande variabilidade do material estudado.

De qualquer forma, fica evidente que, após o tratamento de vaporização, a qualidade da madeira das procedências Urbenville e Dorrigo tornaram-se praticamente iguais. Isso leva a entender que o tratamento de vaporização eliminou as possíveis diferenças no nível das tensões entre as procedên-cias, conforme constatado por Chafe (1979).

\section{CONCLUSÕES}

1) A vaporização das toras, por um período de $20 \mathrm{~h}$, apesar de não eliminar por completo as tensões de crescimento, proporcionou redução significativa das mesmas para as duas procedências estudadas de Eucalyptus dunnii.

2) Em material controle, a procedência Dorrigo apresentou menor nível de tensões de crescimento que a Urbenville. No entanto, após a vaporização das toras, essa vantagem foi eliminada, tornando as duas procedências iguais em relação à intensidade das tensões de crescimento.

\section{REFERÊNCIAS}

1) AGUIAR, O. J. R. Métodos para controle das rachaduras de topo para toras de Eucalyptus grandis Hill ex. Maiden, visando à produção de lâminas para desenrolamento. Piracicaba: 1986. 92f. Dissertação (Mestrado em Engenharia Florestal) - Universidade de São Paulo.

2) CHAFE, S. C. Growth stresses in trees. Australian Forest Research, v.9, p.203-23, 1979.

3) KUBLER, H. Growth Stresses in Trees and Related Wood Properties. Forest Products Abstracts, Farnham Royal, v.10, n.3, p.61-119,1987.

4) LUTZ, J. F., PANZER, H. R. Potential of Brazil-nut for use as venner. USDA Forest Service, Madison, 1969 (Não publicado).

5) OKUYAMA, T.; KANAGAWA, Y.; HATTORI, Y. Reduction of residual stresses in logs by direct heating method. Mokuzai Gakkashi, Tokyo, v.33, n.11, p.837-43, 1987.

6) ROZAS, E. M. Contribuição ao desenvolvimento tecnológico para utilização de madeira serrada de Eucalyptus grandis (Hill Ex Maiden) na geração de produtos com maior valor agregado. Curitiba: 1993. 133f. Dissertação (Mestrado em Engenharia Florestal) - Universidade Federal do Paraná.

7) SKOLMEN, R. G. Heating logs to relieve growth stresses. Forest Products Journal, Madison, v. 17, p.41-2, 1967.

8) U.S. FOREST PRODUCTS LABORATORY. Wood handbook: wood as an engineering material. Washington: U.S. Department of Agriculture, 1987. 466p.

9) WEIK, B. B.; WENGERT, E. M.; SCHROEDER, J.; BRISBIN, R. Practical drying techniques for yellow-poplar S-D-R fliches. Forest Products Journal, Madison, v.34, p.39-44, 1984. 